\section{Commentary: What happens next?}

\author{
Richard D. Mainwaring, MD
}

Transcatheter pulmonary valve replacement (PVR) has become a commonly performed procedure, with approximately 1000 procedures performed in the United States each year. ${ }^{1}$ In their article in this issue of the Journal, Tannous and Nugent provide a very nice summary of the current state of the art for transcatheter PVR. They speculate that continued advances in technology will make it even more feasible to perform transcatheter PVR in the future.

One of the selling points of transcatheter PVR is the simple fact that it is far less invasive. Given a choice between undergoing a catheter-based procedure or having a group of bloodthirsty Neanderthals tearing your chest apart, most people opt for the former. It is also not surprising that patient satisfaction surveys performed immediately after the procedure favor the less-invasive approach. Data indicate that the differential in patient satisfaction widens even further $(P<.001)$ when the Neanderthals are kept far enough away from the survey participants to prevent any form of intimidation. ${ }^{2}$

Unfortunately, that is not the end of the story. Despite the fact transcatheter PVRs have been used clinically for 20 years, and that there is an intense interest and funding by industry, these valves continue to be plagued by numerous problems. Some of these problems were anticipated, such as technical difficulties in the catheterization lab. Perforations, rupture, false aneurysm formation, emergency retrieval, and death all occur at a low but measurable frequency. Greater experience has served to mitigate these complications.

There remain 2 major problems with transcatheter PVR that almost certainly were unanticipated at the beginning

\footnotetext{
From the Division of Pediatric Cardiac Surgery, Stanford University School of Medicine, Lucile Packard Children's Hospital at Stanford, Stanford, Calif

Disclosures: The author reported no conflicts of interest.

The Journal policy requires editors and reviewers to disclose conflicts of interest and to decline handling or reviewing manuscripts for which they may have a conflict of interest. The editors and reviewers of this article have no conflicts of interest.

Received for publication Aug 3, 2020; revisions received Aug 3, 2020; accepted for publication Aug 4, 2020; available ahead of print Aug 7, 2020.

Address for reprints: Richard D. Mainwaring, MD, Stanford University School of Medicine, 300 Pasteur Dr, Falk CVRC, Stanford, CA 94305 (E-mail: mainwaring@stanford.edu).

J Thorac Cardiovasc Surg 2021;162:971-2

$0022-5223 / \$ 36.00$

Copyright (C) 2020 by The American Association for Thoracic Surgery

https://doi.org/10.1016/j.jtcvs.2020.08.006
}

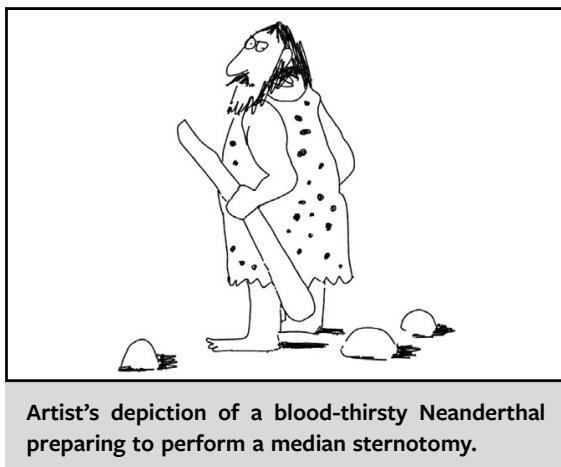

CENTRAL MESSAGE

Transcatheter pulmonary valve replacement may be easier for patients in the short term but maybe not in the long term.

of this grand experiment. The first is that after all these years, the success rate of actually implanting a transcatheter valve is only $58 \%$, meaning that $42 \%$ of patients derive no benefit from having a catheterization procedure. ${ }^{3}$ It is quite disappointing that the "failure" rate is so high, given the cumulative experience, and it remains to be seen whether this can be improved on.

The second major problem is the issue of endocarditis. The data indicate that $12 \%$ of patients with a transcatheter PVR will develop endocarditis, ${ }^{4}$ and some of these patients present with sepsis and multisystem organ failure. These patients probably did not anticipate the need for admission to the intensive care unit when they opted for transcatheter PVR. They might even want to change their answers retroactively on the patient satisfaction survey (without the need for coercion). This issue of endocarditis is a major limitation of this approach, and it does not look like this will be resolved any time soon.

The authors put forth an optimistic view that transcatheter PVR will continue to advance and become an option for most patients with right ventricular dysfunction. However, until the 2 major drawbacks can be overcome, one must maintain a certain amount of skepticism about what happens next.

\section{References}

1. Tannous P, Nugent A. Transcatheter pulmonary valve replacement in native and nonconduit right ventricle outflow tracts. J Thorac Cardiovasc Surg. 2021;162: 967-70.

2. GOK. Influence of intimidation on patient satisfaction surveys. J Neanderthalogy 130,000 BC: 57:121-47 
3. Martin MH, Meadows J, McElhinney DB, Goldstein BH, Bergersen L, Qureshi AM, et al. Safety and feasibility of Melody transcatheter pulmonary valve replacement in the native right ventricular outflow tract. JACC Cardiovasc Intervent. 2018;11:1642-50.
4. McElhinney DB, Sondergaard L, Armstrong AK, Bergersen L, Padera RF, Balzer DT, et al. Endocarditis after transcatheter pulmonary valve replacement. J Am Coll Cardiol. 2018;72:2717-28.
See Article page 967.

\section{Commentary: Innovation in the clinical care of congenital heart defects: Surgeons can and need to weigh in}

David Kalfa, MD, PhD

Tannous and Nugent ${ }^{1}$ offer a very interesting perspective on interventionalists' current thinking and approach to transcatheter pulmonary valve replacement (PVR) for native right ventricle outflow tract (RVOT), the limitations of available devices, and what technologies could become available in the near term. They conclude that transcatheter PVR will become an option for most patients with native RVOT.

This is great news for patients. But there is still a world of uncertainties before transcatheter PVR becomes a safe, widely used, and sustainable option. The durability of transcatheter valves in a native/nonconduit RVOT is still unknown. Selection criteria and the influence of variable anatomy on device performance need to be investigated. The long-term outcomes of valve-in-valve procedures in this highly heterogeneous population remain to be shown.

Once these questions are answered, transcatheterdeployed bioprostheses will not be a panacea anyway. The valves currently being delivered still come with an

From the Section of Pediatric and Congenital Cardiac Surgery, Division of Cardiac, Thoracic and Vascular Surgery, New-York Presbyterian-Morgan Stanley Children's Hospital, Columbia University Medical Center, New York, NY.

Disclosures: The author reported no conflicts of interest.

The Journal policy requires editors and reviewers to disclose conflicts of interest and to decline handling or reviewing manuscripts for which they may have a conflict of interest. The editors and reviewers of this article have no conflicts of interest.

Received for publication Sept 11, 2020; revisions received Sept 11, 2020; accepted for publication Sept 14, 2020; available ahead of print Sept 18, 2020.

Address for reprints: David Kalfa, MD, PhD, Pediatric Cardiac Surgery, Columbia University College of Physicians and Surgeons, New York-Presbyterian Morgan Stanley Children's Hospital, 3959 Broadway, CHN-274, New York, NY 10032 (E-mail: dk2757@cumc.columbia.edu).

J Thorac Cardiovasc Surg 2021;162:972-3

$0022-5223 / \$ 36.00$

Copyright (c) 2020 by The American Association for Thoracic Surgery

https://doi.org/10.1016/j.jtcvs.2020.09.050
Check for updates

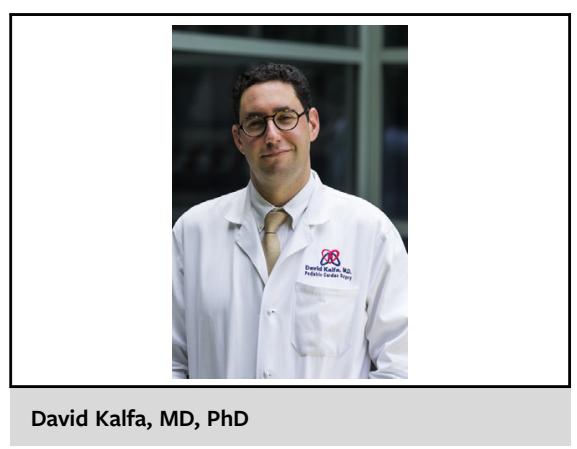

CENTRAL MESSAGE

Transcatheter technology offers

less-invasive options to patients

with native outflow tract but are

not a panacea. Surgeons need to

play an active role in innovation

to develop disruptive devices.

inevitable risk of structural degeneration. These patients have an excellent life expectancy and start the clock of repeat PVR quite early in life. Multiple valve-in-valve transcatheter PVR procedures carry a risk of vascular injury, tricuspid valve injury, and the intracardiac accumulation of large amounts of materials.

Despite these uncertainties and limitations, interventionalists deserve thunderous applause for making the field advance. But sustainable and durable valve replacement in the congenital (especially growing) population remain an unmet clinical need, and there is a lot of room for innovation. Surgeons can weigh in. Surgeons need to weigh in. And surgeons can play a significant role at multiple levels.

On the clinical side, the surgical community needs to keep pushing for sparing the valve at the initial surgery and repairing the valve at redo surgery. Surgeons need to play a proactive role on multidisciplinary teams that include interventionalists and imaging cardiologists to counsel and educate patients on the pros and cons of all options.

On the research side, surgeons (and surgeon-scientists) are ideally placed to develop both evolutionary and revolutionary innovative solutions. Developing a new antistructural 